\title{
BMJ Open Assessment of thyroid cancer risk associated with radiation dose from personal diagnostic examinations in a cohort study of US radiologic technologists, followed 1983-2014
}

\author{
Mark P Little, ${ }^{1}$ Hyeyeun Lim, ${ }^{1}$ Melissa C Friesen, ${ }^{2}$ Dale L Preston, ${ }^{3}$ \\ Michele M Doody, ${ }^{1}$ Alice J Sigurdson, ${ }^{1}$ Gila Neta, ${ }^{4}$ Bruce H Alexander, ${ }^{5}$ \\ Lienard A Chang, ${ }^{1,6}$ Elizabeth K Cahoon, ${ }^{1}$ Steven L Simon, ${ }^{1}$ Martha S Linet, ${ }^{1}$ \\ Cari M Kitahara $^{1}$
}

To cite: Little MP, Lim H, Friesen MC, et al. Assessment of thyroid cancer risk associated with radiation dose from personal diagnostic examinations in a cohort study of US radiologic technologists, followed 1983-2014. BMJ Open 2018;8:e21536. doi:10.1136/ bmjopen-2018-021536

- Prepublication history and additional material for this paper are available online. To view these files, please visit the journal online (http://dx.doi. org/10.1136/bmjopen-2018021536).

Received 8 January 2018 Revised 5 April 2018 Accepted 10 April 2018
Check for updates

For numbered affiliations see end of article.

Correspondence to

Dr Mark P Little;

mark.little@nih.gov

\section{ABSTRACT}

Objective To assess whether personal medical diagnostic procedures over life, but particularly those associated with exposure in adulthood, were associated with increased thyroid cancer risk.

Design Participants from the US Radiologic Technologists Study, a large, prospective cohort, were followed from the date of first mailed questionnaire survey completed during 1983-1989 to the earliest date of self-reported diagnosis of thyroid cancer or of any other cancer than non-melanoma skin cancer (NMSC) in any of three subsequent questionnaires up to the last in 2012-2014.

Setting US nationwide, occupational cohort.

Participants US radiologic technologists with exclusion of: those who reported a previous cancer apart from NMSC on the first questionnaire; those who reported a cancer with an unknown date of diagnosis on any of the questionnaires; and those who did not respond to both the first questionnaire and at least one subsequent questionnaire.

Primary outcome measure We used Cox proportional hazards models with age as timescale to compute HRs and $95 \% \mathrm{Cl}$ for thyroid cancer in relation to cumulative 5-year lagged diagnostic thyroid dose.

Results There were 414 self-reported thyroid cancers $(n=275$ papillary) in a cohort of 76415 persons.

Cumulative thyroid dose was non-significantly positively associated with total (excess relative risk/Gy $=2.29(95 \%$ $\mathrm{Cl}-0.91$ to $7.01, \mathrm{p}=0.19)$ ) and papillary thyroid cancer (excess relative risk/Gy $=4.15(95 \% \mathrm{Cl}-0.39,11.27$, $\mathrm{p}=0.08)$ ) risk. These associations were not modified by age at, or time since, exposure and were independent of occupational exposure.

Conclusion Our study provides weak evidence that thyroid dose from diagnostic radiation procedures over the whole of life, in particular associated with exposure in adulthood, influences adult thyroid cancer risk.

\section{Strengths and limitations of the study}

- Unique aspects of the study include the comprehensive assessment of diagnostic radiation procedures received throughout life that allowed for estimation of medical diagnostic radiation absorbed doses to the thyroid gland, as well as the rich set of covariate information on lifestyle and environmental exposures that allowed for adjustment for potential confounding.

- Additional major strengths are the large size, prospective design, long follow-up and availability of occupational doses.

- A weakness is the reliance on self-reported medical diagnostic procedures and self-reported thyroid cancer diagnosis, although since they are all radiologic technologists, it is expected that their reporting of medical radiation procedures, including diagnostic exams, would be reasonably accurate.

- Another weakness is that medical diagnostic procedures could be given as part of the process of diagnosis of thyroid cancer, so that there could be a type of bias known as reverse causation.

- There are ambiguities in the precise nature of the procedure being used, based on the wording of the questionnaire that the technologists completed, so that the questionnaire does not elicit information on whether the thyroid radionuclide diagnostic procedures being asked about were thyroid scans, a type of imaging exam or ${ }^{131}$ I thyroid uptake tests, a measure of thyroid function.

\section{INTRODUCTION}

Thyroid cancer has been increasing rapidly in the USA ${ }^{1}$ and in other countries. Thyroid cancer is one of the most radiogenic types of cancer, and has been associated with high dose rates of external ionising radiation exposure in the Japanese atomic bomb 
survivors ${ }^{2}$ as well as lower-dose medical exposures. ${ }^{3}$ There are also well-documented excess risks of thyroid cancer following childhood internal exposure to radioiodine from the Chernobyl nuclear accident. ${ }^{45}$ There is significant reduction of relative risk with increasing exposure age, but rather weaker indications of variations of relative risk with time after exposure. ${ }^{26}$ Although there is growing information about thyroid cancer risk after adult exposure, ${ }^{27}$ less is known about thyroid cancer risk after lower-dose external radiation exposures and about risks associated with radiological examinations in adulthood. Per capita population doses associated with many medical diagnostic radiological procedures have been recently increasing in the USA and elsewhere. ${ }^{8}$

Our earlier prospective questionnaire-based cohort investigation of thyroid cancer in relation to self-reported history of personal diagnostic radiological examinations among US radiologic technologists identified an association with dental, but not other higher-dose, diagnostic procedures. ${ }^{9}$ The previous study was based on numbers of procedures, not individually estimated doses.

The present study, the largest investigation of personal diagnostic radiological examinations and thyroid cancer risk, is an extension of the previous study ${ }^{9}$ with an additional estimated 10 years of follow-up, averaging now 22.2 years. To estimate radiation exposure to the thyroid, we used individual assessments of thyroid doses from medical diagnostic procedures. Dose estimates were derived using a novel regression method, based on questionnaire-derived number and type of radiological procedures, combined with estimated time period-specific doses from comprehensive literature review and calculated based on machine parameters reported in the literature for radiological examinations during 1930-2009. ${ }^{10}$ We assessed variations of risk by time since exposure and exposure age, as well as by thyroid cancer histological type. In particular, we assessed contributions to thyroid cancer risk associated with exposure in adulthood.

\section{METHODS}

\section{Study population/follow-up}

The US Radiologic Technologist (USRT) study population and methods are described elsewhere. ${ }^{11}$ Briefly, the US National Cancer Institute, in collaboration with the University of Minnesota and the American Registry of Radiologic Technologists (ARRT), has studied cancer incidence and mortality among 146022 (106953 women) US radiologic technologists who were certified for at least 2years during 1926-1982. ${ }^{11} 12$ Annual follow-up was conducted through yearly recertification with the ARRT. Four different survey questionnaires were administered in the periods 1983-1989, 1994-1998, 2003-2005 and 2012-2014 to collect information on health outcomes (including self-reported thyroid cancer), work history and practices, history of personal medical diagnostic radiological examinations and radiotherapy, demographic characteristics, medical histories and other environmental and lifestyle risk factors. The response rate to the questionnaires among living and located cohort members was approximately $70 \%$ for the first three surveys and $63 \%$ for the last survey, with 110418 individuals completing one or more questionnaires.

We studied radiologic technologists who completed the first questionnaire (1983-1989) and who were followed up for thyroid cancer incidence, reported by the participants in responses to subsequent questionnaires. We excluded: participants who reported a previous cancer apart from non-melanoma skin cancer (NMSC) on the first questionnaire; those who reported a cancer with an unknown date of diagnosis on any of the questionnaires; and those who did not respond to both the first questionnaire and at least one subsequent questionnaire. After these exclusions, 76415 persons were available for analysis (table 1). Follow-up started at the date of completion of the first questionnaire. Follow-up ended on the earliest of (1) last questionnaire answered or (2) first date of diagnosis of any cancer apart from NMSC (including, but not limited to, thyroid cancer). We excluded cancers other than NMSC at baseline because of the potential for radiotherapy in treatment of such cases, doses from which we could not estimate. It was decided that the prevalent thyroid cancer cases at the first questionnaire could not be analysed because of the possibility of recall and selection bias.

\section{Medical diagnostic dose estimation}

In the first questionnaire, information was elicited about the specific types and the number of radiological examinations, and the first year in which each type of examination occurred for specific types of diagnostic radiological procedure. In online supplementary appendix A table A1, we list the types of radiographic examinations for which this information was obtained that involved potential radiation exposure to the thyroid gland. Unfortunately, the specific type of certain medical diagnostic procedure was not specified on the first questionnaire. As discussed below, we assumed that most dental X-rays were bitewing procedures and that most thyroid radionuclide procedures were thyroid scans. Shown in online supplementary file appendix A table A1 are the estimated absorbed doses to the thyroid gland by diagnostic procedure and calendar period, derived from a comprehensive literature review of 14 common types of diagnostic radiological examination. ${ }^{10}{ }^{13}$ For diagnostic x-rays of the collar bone and shoulder, Chang $e a^{10}$ estimated radiological parameters for each procedure (number and type of projections, $\mathrm{kVp}$, field size, $\mathrm{mAs}$ ) from a radiological positioning textbook series ${ }^{14-21}$ and then calculated doses using the Monte Carlo PCXMC code. ${ }^{22}$ Doses for mammography and thyroid scan were assumed to be 0 before 1960, as it was thought unlikely that these types of procedure would have been performed during those early time periods. Self-reports from the second questionnaire were used to derive cohort-level estimates of number of procedures by age, as shown in online supplementary file appendix A table A2.

The doses per diagnostic procedure vary quite markedly by calendar period (see online supplementary file 
Table 1 Thyroid cancers by histological type and other summary data

\section{Characteristics}

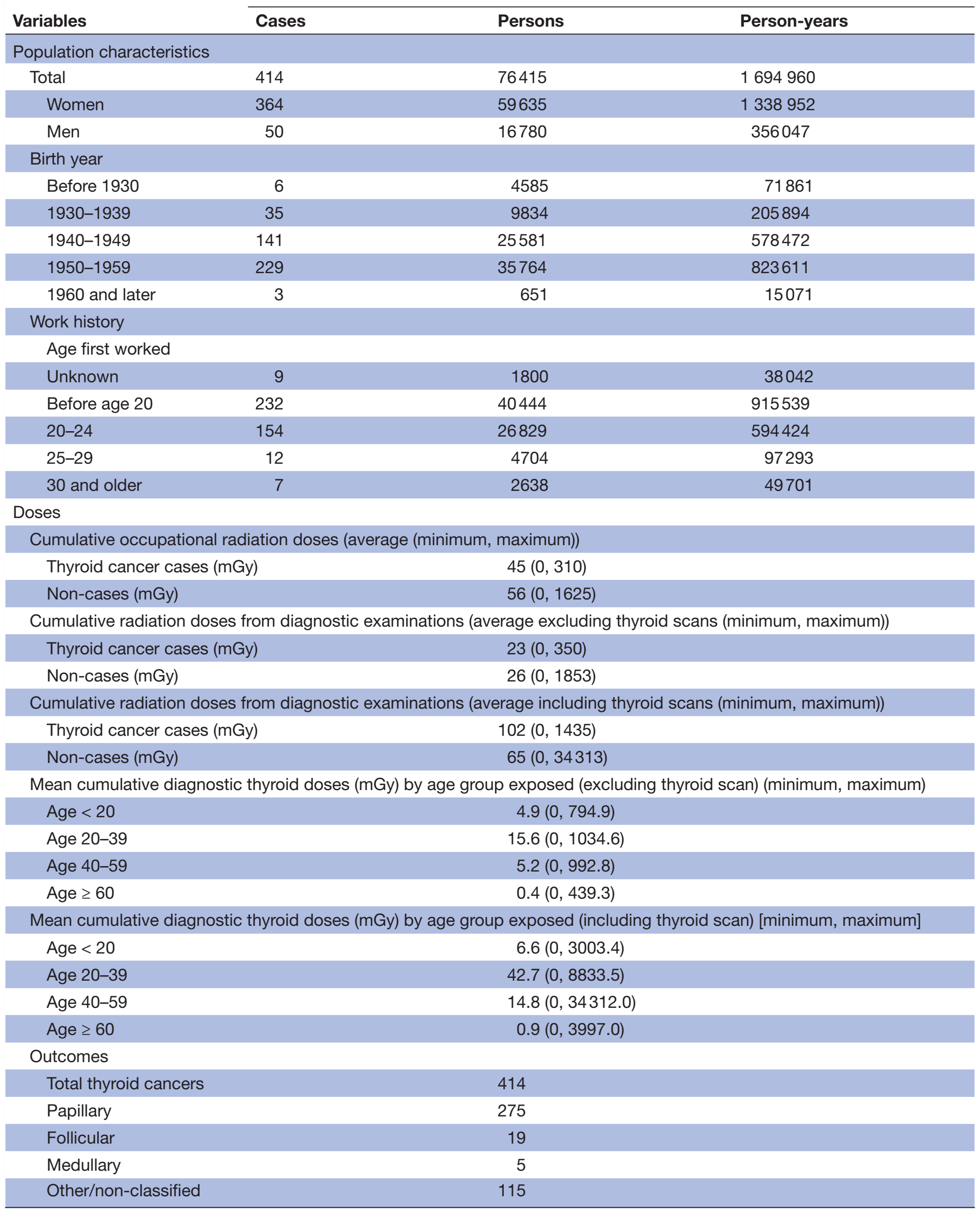


appendix A table A1), emphasising the importance of ascertaining the time distribution of each type of procedure. This was achieved using information from the first questionnaire on number of examinations by type of diagnostic procedure and first year of such diagnostic procedures. This entailed deriving information on the age and calendar period dependent distribution of numbers of procedures from the second questionnaire; information on number of procedures for the periods $<1980,1980$ $1989,>1990$, combined with the subject's birth date and date of response to the second questionnaire, was used to derive the distribution of procedure rates given in online supplementary file appendix A table A2.

The numbers of technologists who either recorded a year of first examination without giving the total number of examinations or recorded the number of examinations without giving the first year of the diagnostic examinations are shown according to specific examination type in online supplementary file appendix B table B1. In these cases, the missing information was estimated from the procedure-specific means by sex and age group (0-19, 20-24, 25-29, 30-34, .., 95-99, >100) at date of completion of first questionnaire.

We itemise in online supplementary file appendix B table B2 the various sensitivity analyses given in online supplementary file appendix B tables B3-B7, and the reasons for doing these.

The combination of per-procedure thyroid dose (see online supplementary file appendix A table A1) and age-specific distribution of number of procedures per year (see online supplementary file appendix A table A2) was then used to derive an array of annual thyroid doses. Since the questionnaire did not ascertain the year or age of each procedure, responses may not accurately reflect the exposures. Thus, sensitivity analyses were conducted in which we assumed either that all procedures occurred within 10 years of the first procedure of each type (see online supplementary file appendix B table B3) or that procedures occurred with a constant frequency per year (see online supplementary file appendix B table B4), ignoring the information in online supplementary file appendix A table A2. Online supplementary file appendix A Supplementary Methods gives further details on the methods used to determine the calendar-year distribution of medical diagnostic doses for each individual in the cohort, and presents a hypothetical calculation of dose.

\section{Statistical methods}

Thyroid cancer risks in the cohort were assessed using Cox proportional hazards models ${ }^{23}$ with age as timescale, in which the relative risk (RR) for individual at age $a$ was given by:

$$
R R_{i}\left[a, D_{i},\left(X_{j i}\right) \mid \alpha,\left(\beta_{j}\right)\right]=\exp \left[\sum_{j=1}^{N} \beta_{j} X_{j i}\right]\left[1+\alpha D_{i}(a-5)\right]
$$

where $D_{i}(a-5)$ is the time-varying cumulative thyroid dose in Gy, lagged by 5 years to allow for disease latency, ${ }^{24}$ $\left(X_{j i}\right)$ are the lifestyle and medical risk factors (other than medical radiation exposure), $\alpha$ is the excess RR coefficient (ERR) per unit dose (Gy), and $\left(\beta_{j}\right)$ are coefficients adjusting for lifestyle risk factors. Additional sensitivity analyses were conducted using lag periods of 0 and 10 years. We also fitted models incorporating separately accumulated 'windows' of dose accumulated by intervals of time since exposure:

$$
\begin{aligned}
& R R_{i}\left[a, D_{i},\left(X_{j i}\right) I,\left(\alpha_{j}\right),\left(\beta_{j}\right)\right]= \\
& \exp \left[\sum_{j=1}^{N} \beta_{j} X_{j i}\right]\left[\begin{array}{c}
1+\alpha_{1}\left[D_{i}(a-5)-D_{i}(a-10)\right]+ \\
\alpha_{2}\left[D_{i}(a-10)-D_{i}(a-15)\right]+ \\
\alpha_{3} D_{i}(a-15)
\end{array}\right]
\end{aligned}
$$

or similar separate accumulations of dose by intervals of exposure age:

$$
\begin{gathered}
R R_{i}\left[a, D_{i},\left(X_{j i}\right) \mathrm{I},\left(\alpha_{j}\right),\left(\beta_{j}\right)\right]=\exp \left[\sum_{j=1}^{N} \beta_{j} X_{j i}\right] \\
{\left[\begin{array}{c}
1+\alpha_{1} D_{i} \min (a-5,20)+ \\
\alpha_{2}\left[D_{i} \min (a-5,40)-D_{i}, \min (a-5,20)\right]+ \\
\alpha_{3}\left[D_{i} \min (a-5,60)-D_{i} \min (a-5,40)\right]+ \\
\alpha_{3}\left[D_{i}(a-5)-D_{i} \min (a-5,60)\right]
\end{array}\right]}
\end{gathered}
$$

All CI and two-sided p values are profile-partial likelihood based, ${ }^{25}$ unless otherwise stated. Models were stratified by sex and year of birth $(<1900,1900-1909,1910-1919$, 1920-1929, 1930-1939, 1940-1949, 1950-1959, 1960+), as these are known to strongly affect thyroid cancer risk. We did not collect information about the source of information used for diagnosis, for example, thyroid cancer screening or symptoms. To account for potential surveillance bias among people with other thyroid conditions who may also be undergoing increased diagnostic procedures and thus have higher dose, we conducted sensitivity analyses by estimating ERRs by excluding groups with the following prevalent conditions determined from the first questionnaire, in particular presence of hyperthyroidism, hypothyroidism, goitre and any other (non-malignant) thyroid pathology (including nodules). Because of the possibility that thyroid radioisotope procedures may be administered for the purpose of diagnosing thyroid cancer, we excluded all thyroid radioisotope diagnostic procedures from the estimation of absorbed thyroid dose. Because of uncertainty associated with the type of dental examinations, certain sensitivity analyses also excluded this group of procedures.

\section{Patient and public involvement}

The development of the research question and outcome measures, specifically thyroid cancer risk associated with protracted low-dose occupational radiation exposure, was not specifically informed by participants' priorities and preferences. During development of the various survey questionnaires, subgroups of radiological technologists participated in focus groups and provided input on the applicability and wording of questions pertaining to work history and radiation exposures. Results are disseminated to participants via periodic newsletters and on the USRT Study website (https://radtechstudy.nci.nih.gov/). Participants were not involved in the recruitment to and 


\begin{tabular}{|c|c|c|}
\hline $\begin{array}{l}\text { Latent period } \\
\text { (years) }\end{array}$ & ERR/Gy (+95\% Cl) & P value* \\
\hline \multicolumn{3}{|c|}{ Excluding thyroid scan doses } \\
\hline 0 & $2.10(-0.97$ to 6.66$)$ & 0.216 \\
\hline 5 & $2.29(-0.91$ to 7.01$)$ & 0.191 \\
\hline 10 & 2.49 (-0.89 to 7.43$)$ & 0.174 \\
\hline 15 & $3.00(-0.74$ to 8.45$)$ & 0.133 \\
\hline \multicolumn{3}{|c|}{ Including thyroid scan doses } \\
\hline 0 & 1.69 (0.81 to 2.83$)$ & $<0.001$ \\
\hline 5 & 1.66 (0.78 to 2.81$)$ & $<0.001$ \\
\hline 10 & 1.55 (0.66 to 2.73$)$ & $<0.001$ \\
\hline 15 & 1.49 (0.54 to 2.75$)$ & $<0.001$ \\
\hline
\end{tabular}

Stratification is by sex and year of birth $(<1900,1900-1909,1910$ 1919, 1920-1929, 1930-1939, 1940-1949, 1950-1959, 1960+). ${ }^{*} \mathrm{P}$ value for improvement in fit compared with null model, that is, significance of the departure of the ERR/Gy from 0 .

ERR, excess relative risk coefficient.

conduct of the study, except in as much as they were part of the underlying cohort and completed questionnaires.

\section{RESULTS}

There were 414 first primary thyroid cancers (excluding prevalent thyroid cancers at baseline) in a cohort of 76415 persons (after omitting those with cancer other than NMSC at baseline) with 1694960 person-years of follow-up (table 1), an average of 22.2 years of follow-up per individual. The mean medical diagnostic dose (excluding thyroid uptake scans) was $23 \mathrm{mGy}$ (range 0 , 350 ) among cases and 26 mGy (range 0,1853 ) among non-cases (table 1). If thyroid uptake scans were included, these figures were considerably higher, $102 \mathrm{mGy}$ (range 0,1435 ) among cases and $65 \mathrm{mGy}$ (range 0, 34,313) among non-cases (table 1). Most of the dose, whether including thyroid uptake scan or not, was incurred at ages 20-39 (table 1). The majority of cancers were papillary thyroid cancers (PTC) $(\mathrm{n}=275)$, with small numbers of follicular $(n=19)$ and medullary $(n=5)$ cancers; there was a large group of thyroid cancers $(n=115)$ from individuals for whom medical records could not be obtained, with thyroid cancer subtype unknown (table 1). Analyses in which thyroid scan dose was excluded and using lag periods of 0 or 15 years showed that increases in the period of latency from 0 to 15 years resulted in a modest strengthening of the trend with dose (table 2). However, when sensitivity analysis was conducted in which thyroid scan dose was included, increasing the latent period results in some weakening of the trend with dose, which would be consistent with there being a degree of reverse causation (table 2). For this reason, most analyses from now on excluded thyroid scan dose. Additional sensitivity analysis shows that little difference was made by excluding dental dose (table 3, see online supplementary file appendix B table B5).

Table 3 and figure 1 demonstrate that there was a non-significant increasing dose response for thyroid cancer, with an ERR/Gy of 2.29 (95\% CI -0.91 to 7.01, $\mathrm{p}=0.191$ ). There was no significant variation of $\mathrm{ERR} / \mathrm{Gy}$

Table 3 Thyroid cancer and papillary thyroid cancer, by time since exposure, exposure age and sex, using cumulative diagnostic thyroid radiation dose

\begin{tabular}{|c|c|c|c|}
\hline \multirow[b]{2}{*}{ Model number } & \multirow[b]{2}{*}{ Statistical model } & \multirow{2}{*}{$\begin{array}{l}\text { All thyroid cancer } \\
\text { ERR/Gy }(+95 \% \mathrm{Cl})\end{array}$} & \multirow{2}{*}{$\begin{array}{l}\text { Papillary thyroid cance } \\
\text { ERR/Gy }(+95 \% \mathrm{Cl})\end{array}$} \\
\hline & & & \\
\hline \multirow[t]{2}{*}{1} & Linear thyroid dose & $2.29(-0.91$ to 7.01$)$ & $4.15(-0.39$ to 11.27$)$ \\
\hline & $P$ value & $0.191^{\star}$ & $0.080^{\star}$ \\
\hline \multirow[t]{4}{*}{2} & Time since exposure 5-9years & $-1.10(-24.84$ to 39.52$)$ & $3.24(-26.16$ to 61.98$)$ \\
\hline & Time since exposure $10-14$ years & $-6.95(-24.49$ to 17.05$)$ & $-12.03(-30.21$ to 18.06$)$ \\
\hline & Time since exposure $15+$ years & $3.49(-0.55$ to 9.07$)$ & 5.27 (0.11 to 13.22$)$ \\
\hline & Heterogeneity $p$ value & $0.578 \dagger$ & $0.441 \dagger$ \\
\hline \multirow[t]{5}{*}{3} & Exposure age $0-19$ years & $4.57(-3.08$ to 16.19$)$ & $6.75(-3.36$ to 23.24$)$ \\
\hline & Exposure age $20-39$ years & 0.15 (-3.98 to 6.24$)$ & $3.31(-2.69$ to 12.42$)$ \\
\hline & Exposure age $40-59$ years & $8.13(-2.51$ to 28.05$)$ & $4.47(-4.24$ to 29.65$)$ \\
\hline & Exposure age $60+$ years & $-36.22(<-100$ to $>100)$ & $-18.23(<-100$ to $>100)$ \\
\hline & Heterogeneity $p$ value & $0.724 \dagger$ & $0.971 \dagger$ \\
\hline \multirow[t]{3}{*}{4} & Men & 3.48 (-2.62 to 20.85$)$ & $2.60(-6.42$ to 30.96$)$ \\
\hline & Women & 2.05 (-1.33 to 7.22$)$ & $4.35(-0.45$ to 12.14$)$ \\
\hline & Heterogeneity $p$ value & $0.797 \dagger$ & $0.848 \dagger$ \\
\hline
\end{tabular}

Stratification is by sex and year of birth (<1900, 1900-1909, 1910-1919, 1920-1929, 1930-1939, 1940-1949, 1950-1959, 1960+).

${ }^{*} \mathrm{P}$ value for improvement in fit compared with null model, that is, significance of the departure of the ERR/Gy from 0 .

†P value for improvement in fit compared with simple linear model 1.

ERR, excess relative risk coefficient. 


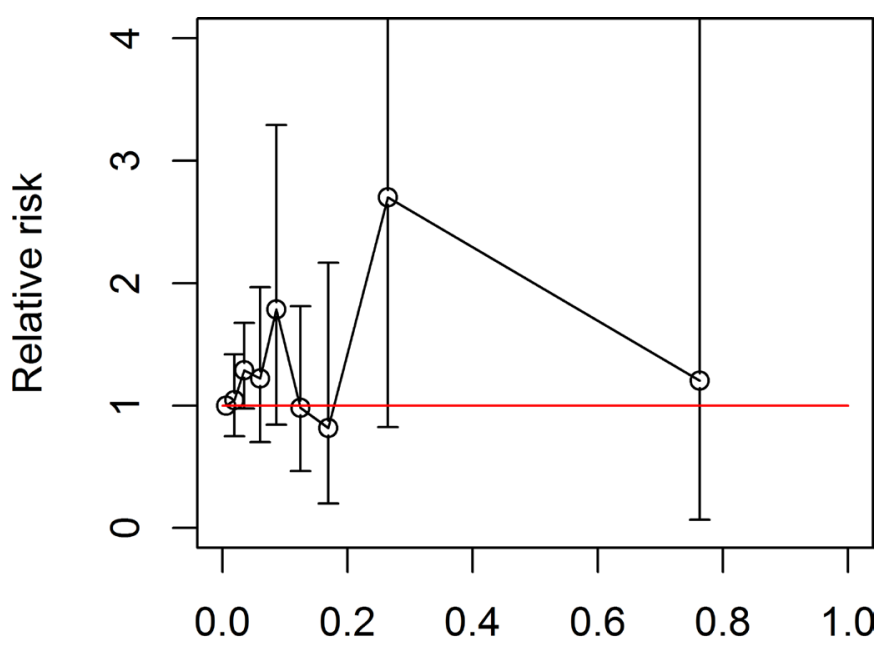

Thyroid dose (Gy)

Figure 1 Thyroid cancer diagnostic radiation dose response (relative risk $+95 \% \mathrm{Cl}$ ). Evaluated in relation to cumulative thyroid dose, using stratification by sex and year of birth (<1900, 1900-1909, 1910-1919, 1920-1929, 1930-1939, 1940-1949, 1950-1959, 1960+). Red line is relative risk=1.

by time since exposure or exposure age ( $p>0.5$, table 3$)$, although there were weak indications that risk increased with increasing years after exposure and with decreasing exposure age (table 3 ). Tables 3 and 4 demonstrate that the dose response for PTC had borderline significant positive trend, with an ERR/Gy of 4.15 (95\% CI -0.39 to 11.27, $p=0.080)$; there were weak indications $(p>0.4)$ that relative risk of PTC increased with increasing time since exposure and decreasing exposure age. There were no indications of excess risk for any type of thyroid cancer other than PTC (table 4). There were only weak indications of excess thyroid cancer risk associated with any exposure age group $(20-39,40-59,60+)$ in adulthood. Table 3 demonstrates that the ERR/Gy for PTC was slightly higher in women, 4.35 (95\% CI -0.45 to $12.14, \mathrm{p}=0.085$ ), than in men, 2.60 (95\% CI -6.42 to $30.96, p=0.727)$, but the difference was not statistically significant $(\mathrm{p}=0.848)$. There were similar findings for all thyroid cancers.

Sensitivity analysis, in which all persons with various types of non-malignant thyroid disease at first questionnaire were excluded, demonstrated that there was a slight reduction of trend for thyroid cancer, so that the ERR/Gy became $1.62(95 \% \mathrm{CI}-1.89$ to $7.32, \mathrm{p}=0.445)$, as well as for PTC, with ERR/Gy 1.80 (95\% CI -2.59 to 9.61, p=0.519) (see online supplementary file appendix B table B6).

Sensitivity analyses in which we assumed that all procedures occurred within 10 years of the first procedure of each type (see online supplementary file appendix B table B3) or that procedures occurred with a constant frequency per year (see online supplementary file appendix B table B4) yielded slightly lower dose trends.

A sensitivity analysis in which we compared the model incorporating only medical diagnostic dose (table 3) with one that simultaneously adjusted for medical and occupational dose (see online supplementary file appendix B table B7) did not materially affect the trend with diagnostic dose, whether for all thyroid cancer or PTC.

\section{DISCUSSION}

In this large cohort of US radiologic technologists, we did not find a clear positive association between risk of thyroid cancer and absorbed thyroid dose from medical diagnostic radiation procedures received across the life course. In particular, there were only weak indications of excess thyroid cancer risk associated with exposure in adulthood. A novel feature of the study is the methodology used for assessment of medical diagnostic radiation dose, using a regression model to assess frequency of diagnostic dose combined with a literature-based lookup table of thyroid dose per diagnostic procedure. As such, it marks a substantial advance over the previous analysis, ${ }^{9}$ which did not incorporate individual diagnostic doses in the analysis. Follow-up has also been somewhat extended from the cohort previously analysed, ${ }^{9}$ which included 251 thyroid cancers, compared with the 414 assessed here.

There is some evidence that hypothyroidism and thyroiditis are associated with thyroid cancer. ${ }^{26}{ }^{27}$ There are also indications in the Japanese atomic bomb survivors $^{28}$ and in persons treated for cancer ${ }^{29}$ of associations of radiation dose with thyroid nodule prevalence. In paediatric Chernobyl-exposed groups, hypothyroidism is associated with radiation dose. ${ }^{30} 31$ Removing people with these benign thyroid conditions might therefore amount to removing persons with an intermediate phenotype, which would result in weakening if not elimination of the dose response, as indeed happens here to some extent (see online supplementary file appendix B table B6).

Table 4 Thyroid cancer risk by subtype. Thyroid scan is not used, and stratification is by sex and year of birth $(<1900,1900-$ 1909, 1910-1919, 1920-1929, 1930-1939, 1940-1949, 1950-1959, 1960+)

\begin{tabular}{lclr}
\hline Thyroid cancer subtype & ERR/Gy (+95\% Cl) & P value* & Cases \\
\hline Follicular & $-0.29(-5.75$ to 29.08) & 0.964 & 19 \\
Medullary & $-22.47(-42.59$ to 48.92$)$ & 0.277 & 5 \\
Papillary & $4.15(-0.39$ to & 0.080 & 275 \\
Other and unclassified thyroid cancer & $-0.08(-2.99$ to 8.03$)$ & 0.978 & 115
\end{tabular}

${ }^{*} \mathrm{P}$ value for improvement in fit compared with null model, that is, significance of the departure of the ERR/Gy from 0 . ERR, excess relative risk coefficient. 
The indications of excess thyroid cancer risk that are observed here, most pronounced for PTC, with an ERR/Gy of 4.15 (95\% CI -0.39 to 11.27) (table 3, online supplementary file appendix B table B8), are comparable with those in other groups exposed in adulthood; as the dose distribution of table 1 indicates, young adulthood (ages 20-39) is arguably the most appropriate exposure age to compare with. As summarised in online supplementary file appendix B table B8, there are various groups exposed to ionising radiation in adulthood for whom there are indications of excess risk. In particular, there are modest but non-statistically significant excess risks in the Japanese atomic bomb survivors exposed at age $>20$ and among UK nuclear workers, with ERR/Gy of $0.27(95 \% \mathrm{CI}<0 \text { to } 1.07)^{2}$ and $3.24(95 \%$ CI -0.48 to 17.51 ), ${ }^{7}$ respectively (see online supplementary file appendix B table B8). More controversially, a Chernobyl-liquidator case-control study showed a larger and statistically significant association between thyroid dose and thyroid cancer incidence, with an ERR/Gy of 3.8 $(95 \% \text { CI } 1.0 \text { to } 10.9)^{32}$ (see online supplementary file appendix B table B8). Recall bias may have also influenced the results of the Chernobyl-liquidator study, as doses for cases and controls were derived from interviews about their work conditions, many years after the Chernobyl accident. The indication of reduction of ERR with increasing exposure age (table 3 ) is also consistent with what is seen in the Japanese atomic bomb survivors $^{2}$ and in many other exposed groups. ${ }^{33}$

\section{Strengths and limitations}

Unique aspects of this study include the comprehensive assessment of diagnostic radiation procedures received throughout life that allowed for estimation of medical diagnostic radiation absorbed doses to the thyroid gland, as well as the rich set of covariate information on lifestyle and environmental exposures that allowed for adjustment for potential confounding. Additional major strengths are the large size, prospective design and long follow-up. The availability of occupational thyroid dose is also a significant strength. Comparison of the analyses of table 3 and online supplementary file appendix B table B7 suggests that occupational radiation dose does not confound the relationship of thyroid cancer with medical diagnostic dose. A weakness is the reliance on self-reported medical diagnostic procedures and self-reported thyroid cancer diagnosis. However, since they are all radiological technologists, it is expected that their reporting of medical radiation procedures, including diagnostic examinations, would be reasonably accurate. Additionally, $96.6 \%$ of the thyroid cancers reported on the second survey for which medical records were obtained were found to be accurately reported. ${ }^{34}$

Potentially the most substantial complication of the study is that medical diagnostic procedures could be given as part of the process of diagnosis of thyroid cancer, so that there could be a type of bias known as reverse causation. This is particularly problematic for thyroid radioisotope procedures. Because of the substantial likelihood that thyroid scans are given as part of the diagnosis of thyroid cancer, we excluded all thyroid radioisotope diagnostic procedures from dose assessments. Although the magnitude of the dose response did not markedly change if thyroid scan dose was included, increasing the dose lag from 0 to 15 years caused the ERR/Gy to modestly decrease (table 2). This is the direction one would expect the ERR/Gy to change if reverse causation played a role, since diagnostic procedures would likely cluster in the period immediately before cancer diagnosis. When thyroid scan dose was excluded, the ERR/Gy increased with increasing lag, suggesting that reverse causation was unlikely (table 2). Information on certain medical diagnostic procedures was not elicited in the first questionnaire, the most significant of which is computerised tomography. The errors resulting from omission of such doses should not be correlated with the other medical diagnostic doses, and so to first order should be of approximately Berkson form. As such, these would not be expected to bias the dose response, although they could inflate the variance of trend estimates. ${ }^{35} 36$ The potential for screening bias due to differences in healthcare utilisation patterns within the cohort seems unlikely given the homogeneous nature of the cohort and their similar access to healthcare.

There are certain crucial ambiguities in the precise nature of the procedure being used, based on the wording of the first questionnaire. For example, the questionnaire does not elicit information on whether the thyroid radionuclide diagnostic procedures being asked about were thyroid scans, a type of imaging examination, or ${ }^{131}$ I thyroid uptake tests, a measure of thyroid function, and which is not an imaging procedure. Online supplementary file appendix A table A1 indicates that there were substantial differences in dose from the two types of diagnostic thyroid examination. Information was also not collected on the type of dental procedures. We made the assumption that most such procedures were dental bitewing X-rays, which is likely to be the case ${ }^{37-40}$ but inevitably, there is uncertainty here. Exclusion of such dental doses did not make much difference to the dose trends (table 3, see online supplementary file appendix B table B5).

Follow-up was censored at the date of the last questionnaire answered. The plausible assumption was made that censoring was non-informative with respect to the endpoint (thyroid cancer) being considered.

Inevitably, there is some loss of information because follow-up only commenced at the date of completion of the first questionnaire, and we excluded any persons reporting any cancer other than NMSC at that point. This should not be a source of bias. However, if the ERR/Gy were to decrease with time since exposure, as has been suggested in a number of childhood-exposed groups, ${ }^{3641}$ it may be that the statistical power of the study would be reduced. 


\section{CONCLUSIONS}

In summary, we found little evidence of increased thyroid cancer risk associated with greater medical diagnostic radiation exposure across the lifespan, in particular only weak indications of excess thyroid cancer risk associated with adult exposure.

\section{Author affiliations}

${ }^{1}$ Radiation Epidemiology Branch, Division of Cancer Epidemiology and Genetics, National Cancer Institute, NIH, DHHS, Bethesda, Maryland, USA

${ }^{2}$ Occupational and Environmental Epidemiology Branch, Division of Cancer Epidemiology and Genetics, National Cancer Institute, NIH, DHHS, Bethesda, Maryland, USA

${ }^{3}$ Hirosoft International, Eureka, California, USA

${ }^{4}$ Division of Cancer Control and Population Sciences, National Cancer Institute, NIH, DHHS, Bethesda, Maryland, USA

${ }^{5}$ Division of Environmental Health Sciences, School of Public Health, University of Minnesota, Minneapolis, Minnesota, USA

${ }^{6}$ Department of Radiation Safety and Imaging Physics, Houston Methodist Hospital, Houston, Texas, USA

Acknowledgements The authors would like to thank the two referees for their detailed and helpful comments, the radiologic technologists who participated in the study, Dr Jerry Reid of the American Registry of Radiologic Technologists for continued support, Diane Kampa and Allison Iwan of the University of Minnesota for study management and data collection and Jeremy Miller of Information Management Services for data preparation.

Contributors MPL, CMK, MSL, AJS, SLS and HL conceived and designed the study, and produced an analytical plan. MSL, HL, MMD, AJS, BHA and MPL were responsible for acquisition and processing of data (including questionnaire and cancer validation data). SLS, LAC, DLP, MMD, MSL, BHA and MPL were responsible for dose estimation and validation. MPL was responsible for data analysis. MPL, MCF, HL, CMK, BHA, AJS, MSL, MMD, EKC, SLS and GN interpreted the results. MPL produced a first draft of the manuscript. All authors reviewed the manuscript and provided intellectual input. MPL, CMK and MSL are guarantors.

Funding This work was supported by National Institutes of Health Intramural Research Program, but otherwise received no specific grant from any funding agency in the public, commercial or not-for-profit sectors. This work was funded by the Intramural Research Program of the Division of Cancer Epidemiology and Genetics, National Cancer Institute, National Institutes of Health.

Competing interests None declared.

Patient consent Obtained.

Ethics approval This study has been approved annually by the National Cancer Institute Special Studies Institution Review Board and by the University of Minnesota Institution Review Board.

Provenance and peer review Not commissioned; externally peer reviewed. Data sharing statement All data used can be obtained from MPL on request.

Open Access This is an Open Access article distributed in accordance with the Creative Commons Attribution Non Commercial (CC BY-NC 4.0) license, which permits others to distribute, remix, adapt, build upon this work non-commercially, and license their derivative works on different terms, provided the original work is properly cited and the use is non-commercial. See: http://creativecommons.org/ licenses/by-nc/4.0/

(c) Article author(s) (or their employer(s) unless otherwise stated in the text of the article) 2018. All rights reserved. No commercial use is permitted unless otherwise expressly granted.

\section{REFERENCES}

1. Lim H, Devesa SS, Sosa JA, et al. Trends in thyroid cancer incidence and mortality in the United States, 1974-2013. JAMA 2017:317:1338-48.

2. Furukawa K, Preston D, Funamoto S, et al. Long-term trend of thyroid cancer risk among Japanese atomic-bomb survivors: 60 years after exposure. Int J Cancer 2013;132:1222-6.
3. Lubin JH, Adams MJ, Shore R, et al. Thyroid cancer following childhood low-dose radiation exposure: a pooled analysis of nine cohorts. J Clin Endocrinol Metab 2017;102:2575-83.

4. Little MP, Kukush AG, Masiuk SV, et al. Impact of uncertainties in exposure assessment on estimates of thyroid cancer risk among Ukrainian children and adolescents exposed from the Chernobyl accident. PLoS One 2014;9:e85723.

5. Little MP, Kwon D, Zablotska LB, et al. Impact of uncertainties in exposure assessment on thyroid cancer risk among persons in Belarus exposed as children or adolescents due to the Chernobyl accident. PLoS One 2015;10:e0139826.

6. Veiga LH, Holmberg E, Anderson $\mathrm{H}$, et al. Thyroid cancer after childhood exposure to external radiation: an updated pooled analysis of 12 studies. Radiat Res 2016;185:473-84.

7. Muirhead CR, O'Hagan JA, Haylock RGE, et al. Mortality and cancer incidence following occupational radiation exposure: third analysis of the National Registry for Radiation Workers. Br J Cancer 2009;100:206-12.

8. National Council on Radiation Protection and Measurements (NCRP). Ionizing radiation exposure of the population of the United States. 7910 Woodmont Avenue, Suite 400 / Bethesda, MD 20814-3095, USA: National Council on Radiation Protection and Measurements (NCRP). Report No. 160, 2009:1-402.

9. Neta G, Rajaraman P, Berrington de Gonzalez A, et al. A prospective study of medical diagnostic radiography and risk of thyroid cancer. Am J Epidemiol 2013;177:800-9.

10. Chang LA, Miller DL, Lee C, et al. Thyroid radiation dose to patients from diagnostic radiology procedures over eight decades: 19302010. Health Phys 2017;113:458-73.

11. Preston DL, Kitahara CM, Freedman DM, et al. Breast cancer risk and protracted low-to-moderate dose occupational radiation exposure in the US Radiologic Technologists Cohort, 1983-2008. Br $J$ Cancer 2016:115:1105-12.

12. Mohan AK, Hauptmann M, Freedman DM, et al. Cancer and other causes of mortality among radiologic technologists in the United States. Int J Cancer 2003;103:259-67.

13. Melo DR, Miller DL, Chang L, et al. Organ doses from diagnostic medical radiography - trends over eight decades (1930 to 2010). Health Phys 2016;111:235-55.

14. Bontrager KL. Textbook of radiographic positioning and related anatomy. 3rd edn. St Louis, Missouri: C.V. Mosby, 1993.

15. Bontrager KL. Textbook of radiographic positioning and related anatomy. 4th edn. St Louis, Missouri: C.V. Mosby, 1997.

16. Bontrager KL. Textbook of radiographic positioning and related anatomy. 5th edn. St Louis, Missouri: C.V. Mosby, 2001.

17. Clark KC. Positioning in radiography. St Louis, Missouri: C.V. Mosby, 1939.

18. Clark KC. Positioning in radiography. 5th edn. London: William Heinemann (Medical Books) Ltd, 1949.

19. Clark KC. Positioning in radiography. 7th edn. London: William Heinemann (Medical Books) Ltd / llford Ltd, 1956.

20. Clark KC. Positioning in radiography. 8th edn. London: William Heinemann (Medical Books) Ltd / llford Ltd, 1967.

21. Clark KC, McInnes J. Positioning in radiography. 9th edn. London: William Heinemann Ltd / llford Ltd, 1973.

22. Tapiovaara M, Siiskonen T. PCXMC release 2.0. Finland: STUK, 2017.

23. Cox DR. Regression models and life-tables. $J$ Royal Statist Soc Series B 1972;34:187-220.

24. Little MP, Azizova TV, Bazyka D, et al. Systematic review and metaanalysis of circulatory disease from exposure to low-level ionizing radiation and estimates of potential population mortality risks. Environ Health Perspect 2012;120:1503-11.

25. McCullagh P, Nelder JA. Generalized linear models. Monographs on statistics and applied probability 37. 2nd edn. Boca Raton, FL: Chapman and Hall/CRC, 1989:1-526.

26. Guarino V, Castellone MD, Avilla E, et al. Thyroid cancer and inflammation. Mol Cell Endocrinol 2010;321:94-102.

27. Lee JH, Kim Y, Choi JW, et al. The association between papillary thyroid carcinoma and histologically proven Hashimoto's thyroiditis: a meta-analysis. Eur J Endocrinol 2013;168:343-9.

28. Imaizumi M, Ohishi W, Nakashima E, et al. Association of radiation dose with prevalence of thyroid nodules among atomic bomb survivors exposed in childhood (2007-2011). JAMA Intern Med 2015;175:228-36.

29. Ding SH, Pledge SD, Harrison BJ, et al. The incidence of thyroid abnormalities in adults irradiated for lymphoma. Int $J$ Oncol 2002;20:1065-9.

30. Ostroumova E, Brenner A, Oliynyk V, et al. Subclinical hypothyroidism after radioiodine exposure: Ukrainian-American cohort study of thyroid cancer and other thyroid diseases after 
the Chornobyl accident (1998-2000). Environ Health Perspect 2009;117:745-50.

31. Ostroumova E, Rozhko A, Hatch M, et al. Measures of thyroid function among Belarusian children and adolescents exposed to iodine-131 from the accident at the Chernobyl nuclear plant. Environ Health Perspect 2013;121:865-71.

32. Kesminiene A, Evrard AS, Ivanov VK, et al. Risk of thyroid cancer among Chernobyl liquidators. Radiat Res 2012;178:425-36.

33. United Nations Scientific Committee on the Effects of Atomic Radiation (UNSCEAR). UNSCEAR 2006 Report. Annex A. Epidemiological Studies of Radiation and Cancer. New York: United Nations, 2008:13-322.

34. Sigurdson AJ, Doody MM, Rao RS, et al. Cancer incidence in the US radiologic technologists health study, 1983-1998. Cancer 2003;97:3080-9.

35. Carroll RJ, Ruppert D, Stefanski LA, et al. Measurement error in nonlinear models. A modern perspective. Boca Raton, FL: Chapman and Hall/CRC, 2006:1-488.
36. Stram DO, Preston DL, Sokolnikov M, et al. Shared dosimetry error in epidemiological dose-response analyses. PLoS One 2015;10:e0119418.

37. Manny EF, Carlson KC, McClean PM, et al. An overview of dental radiography. Rockville, MD, USA: National Center for Health Care Technology, 1980:45+viii.

38. Matteson SR, Morrison WS, Stanek EJ, 3rd, et al. A survey of radiographs obtained at the initial dental examination and patient selection criteria for bitewings at recall. J Am Dent Assoc 1983;107:586-90.

39. Gilbert GH, Weems RA, Shelton BJ. Incidence of dental radiographic procedures during a 48-month population-based study of dentate adults. Oral Surg Oral Med Oral Pathol Oral Radiol Endod 2003;96:243-9.

40. Haddon W, Jr, Carlos JP, Ast DB. Frequency of dental X-ray examinations in a New York county. Public Health Rep 1962;77:525-32.

41. Adams MJ, Shore RE, Dozier A, et al. Thyroid cancer risk 40+ years after irradiation for an enlarged thymus: an update of the Hempelmann cohort. Radiat Res 2010;174:753-62. 